\title{
Process intensification of 2-ethylhexyl caprylate/caprate synthesis via a pulsed loop reactor: multi-objective optimization
}

\begin{abstract}
This work proposes the optimization of 2-ethylhexyl (2-EH) caprylate/caprate synthesis in a pulsed loop reactor, and the energy efficiency of the reactor was assessed. 2-EH caprylate/caprate can be used as a biodegradable base fluid. Only $0.4 \mathrm{wt} \%$ catalyst concentration was used in the reaction. The face-centred central composite design (FCCD) experiment coupled response surface methodology (RSM) has been implemented to screen independent parameters. The optimization process showed that vacuum pressure was the most influential factor followed by oscillation speed, temperature and time. The maximum conversion of $98 \%$ and yield of $89 \%$ were achieved under optimal conditions of $78{ }^{\circ} \mathrm{C}$, $10 \mathrm{mbar}, 20 \mathrm{~min}$ and $155 \mathrm{rpm}$. Meanwhile, energy balance calculation indicated that the usage of low vacuum pressure not only significantly reduced the total heat duty from $1381 \mathrm{~kJ}(1 \mathrm{~atm})$ to $823 \mathrm{~kJ}$ (10 mbar) but also alleviated the reaction temperature from $172{ }^{\circ} \mathrm{C}(1 \mathrm{~atm})$ to $78^{\circ} \mathrm{C}$ (10 mbar). The calculation also demonstrated that the reflux-stirred tank reactor produced a lower conversion and yield of ester yet $6 \mathrm{~kJ}$ higher total heat duty compared to the pulsed loop reactor, indicating a cost-saving with the pulsed loop reactor.
\end{abstract}

Keyword: 2-ethylhexyl ester; Pulsed loop reactor; Optimization; Transesterification; Drilling fluid 